\section{Category}

Metal-Mediated

Synthesis

\section{Key Words}

arylmagnesium reagents

iron

catalysis

G. CAHIEZ,* C. CHABOCHE, F. MAHUTEAU-BETZER, M. AHR (CNRS-UCP-ESCOM, CERGYPONTOISE, FRANCE)

Iron-Catalyzed Homo-Coupling of Simple and Functionalized Arylmagnesium Reagents

Org. Lett. 2005, 7, 1943-1946.

\title{
Iron-Catalyzed Homo-Coupling of Arylmagnesium Reagents
}
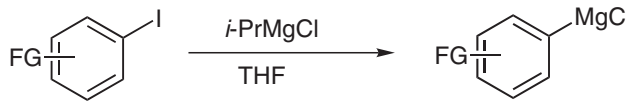

high yields

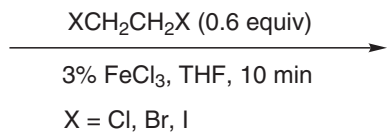

$\mathrm{X}=\mathrm{Cl}, \mathrm{Br}, \mathrm{I}$

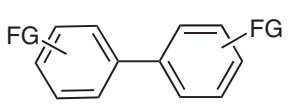

$63-96 \%$

$\mathrm{FG}=\mathrm{Alk}, \mathrm{AlkO}, \mathrm{CN}, \mathrm{CO}_{2} \mathrm{Et}$, amide, etc
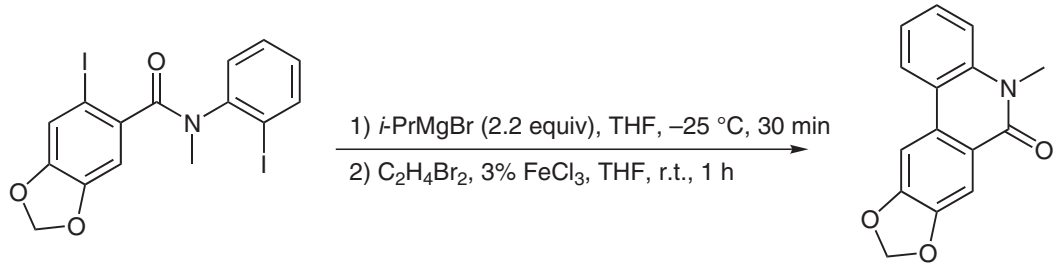

$\mathrm{N}$-methylcrinasiadine $39 \%$ yield

Significance: A very simple and convenient method for preparation of symmetrical biaryls and bis-heteroaryls from corresponding aryl- and hetaryl halides. Various functionalized Grignard reagents can be used in the reaction. The intramolecular variant allows synthesizing interesting polycyclic systems.
Comment: The preparation of functionalized arylmagnesium compounds can be readily performed by using a halogen-magnesium exchange reaction (see, for example: A. Krasovskiy, P. Knochel Angew. Chem. Int. Ed. 2004, 43, 3333-3336) and references cited therein). There was still a need for a simple, cheap and reliable method for the homocoupling of the highly functionalized aryl Grignard reagents. Use of $\mathrm{FeCl}_{3}$ as a catalyst makes it also environmentally friendly and convenient for large scale synthesis. 